\title{
A Case of Acute Viral Encephalitis: Important Aspects and Related Literature Review of Sri Lankan Studies
}

Ariyarathna HTDW*

Department of Forensic Medicine, Faculty of Medical Sciences, University of Sri Jayewardenepura. Sri Lanka.

\begin{abstract}
Encephalitis in otherwise healthy and normal children causes many untimely deaths, giving rise to unexpected complications for physicians, forensic pathologists, and parents alike. Instead of resorting to extensive diagnostic options, aetiology can be identified in only around half of such cases. The case under discussion is a diagnosed case of viral encephalitis and the author attempts to discuss the multiple aspects surrounding the case. The victim was a previously healthy 9-year-old girl who presented with a three-day history of fever, vomiting, and altered consciousness with an episode of convulsion. No causative organism was identified while she was being treated. The histology revealed typical features of viral encephalitis along with other complications. The parental negligence could have been a contributory factor for her demise. Despite high fever with altered consciousness and convulsion, it had taken two days to diagnose her for having encephalitis upon admission. The forensic pathologist was inquired about the cause of her illness many times by the grieving parents. The parental grief was extensive in this case and the establishment of centres to deal with such encounters is suggested.
\end{abstract}

Keywords: Viral encephalitis, causative agent, high fatality, parental grief, histopathology, Sri Lankan studies, delayed treatments

Received: 28 Oct, Revised version accepted: 23 Dec 2020, Published: 31 Dec 2020. *Corresponding author: Ariyarathna HTDW, $\triangle$ Email: ariyaratna@sjp.ac.lk (D) https://orcid.org/0000-0002-4266-5508

Cite this article as: Ariyarathna HTDW. A Case of Acute Viral Encephalitis: Important Aspects and Related Literature Review of Sri Lankan Studies. Medico-Legal Journal of Sri Lanka, 2020;8(2):28-31. DOI: http://dx.doi.org/10.4038/mljsl.v8i2.7422

Copyright: @ 2019 with the Medico-legal Journal of Sri Lanka.

This is an open-access article distributed under the terms of the Creative Commons Attribution 4.0 International License, which permits unrestricted use, distribution, and reproduction in any medium provided the original author and source are credited.

\section{Introduction}

It is necessary for a patient to present with features of alteration of consciousness or personality changes to continue for more than 24 hours, the onset of fever, and compatible features observed through imaging techniques or by EEG changes in order to be diagnosed as having encephalitis. ${ }^{[1]}$

The effects of encephalitis may range from minor flu-like symptoms to permanent neurological damage and even death. The course of the illness is highly unpredictable. Therefore, a timely diagnosis may at least help for a better outcome. To date, specific-antiviral treatments have not been found for many of the causative agents. The medication acyclovir, used for herpes simplex encephalitis, and other immuno-modulatory drugs (steroids or immunoglobulins) used for autoimmune encephalitis are two drugs that are generally used in treatment. Encephalitis is a disease entity that even with sophisticated $21^{\text {st }}$-century drugs and management facilities can turn out to be a frightening condition, eg. Herpes simplex encephalitis (even with a recognized drug). The parents of this victim were extremely difficult to be convinced that encephalitis is at times a deadly disease in spite of being provided ${ }^{[2]}$ with multiple explanations at multiple occasions. Their grief reaction was so intense that they themselves were clinically depressed. However, the author believes that if the parents had admitted the girl soon after her generalized ill health the outcome would have been somewhat better. The parents were repeatedly inquiring from the forensic pathologist about the underlying cause of her illness. It was impossible to provide a convincing explanation due to the inherent nature of viral encephalitis. There had been a delay of five days altogether in diagnosing the condition amidst all of the convincing signs and symptoms. A revisit to that fact is also required.

\section{Case report}

A 9-year-old female was presented to the hospital with a three-day history of fever, vomiting, and gradual onset of confusion, aggression and, loss of consciousness with a fit that lasted for a few minutes before admission. Ensuing day 5, the patient was ventilated and managed as a case of suspected meningo-encephalitis, status epilepticus, and sepsis. By day seven of the illness, she was diagnosed to have undergone multi-organ failure, sepsis, and 
encephalitis (Reports of lumbar puncture, MRI, EEG were suggestive of encephalitis). Influenza A \& B, Epstein Bar virus, cytomegalovirus were negative for PCR. Leptospirosis, dengue, and rabies were all negative. Hanta virus and Japanese encephalitis (JE) were also tested negative. She tested negative for the Mantoux test. Chest X- rays were also normal. The stool was negative for enterovirus. Blood culture was positive for coagulase-negative Staphylococcus species and Acinetobacter species. She had been given acyclovir. Gradually she became deeply comatose with cortical damage. In the end, brain death was confirmed after 28 days. The child's immunization was on par and there was no history of travel abroad and pets.

An inquest was ordered as the wish of the paediatrician. The postmortem showed features of encephalitis, sepsis along with renal failure. The brain showed lymphocytic predominant perivascular cuffing and brain oedema (Fig: 1\&2). No Negri bodies or viral inclusions were identified.
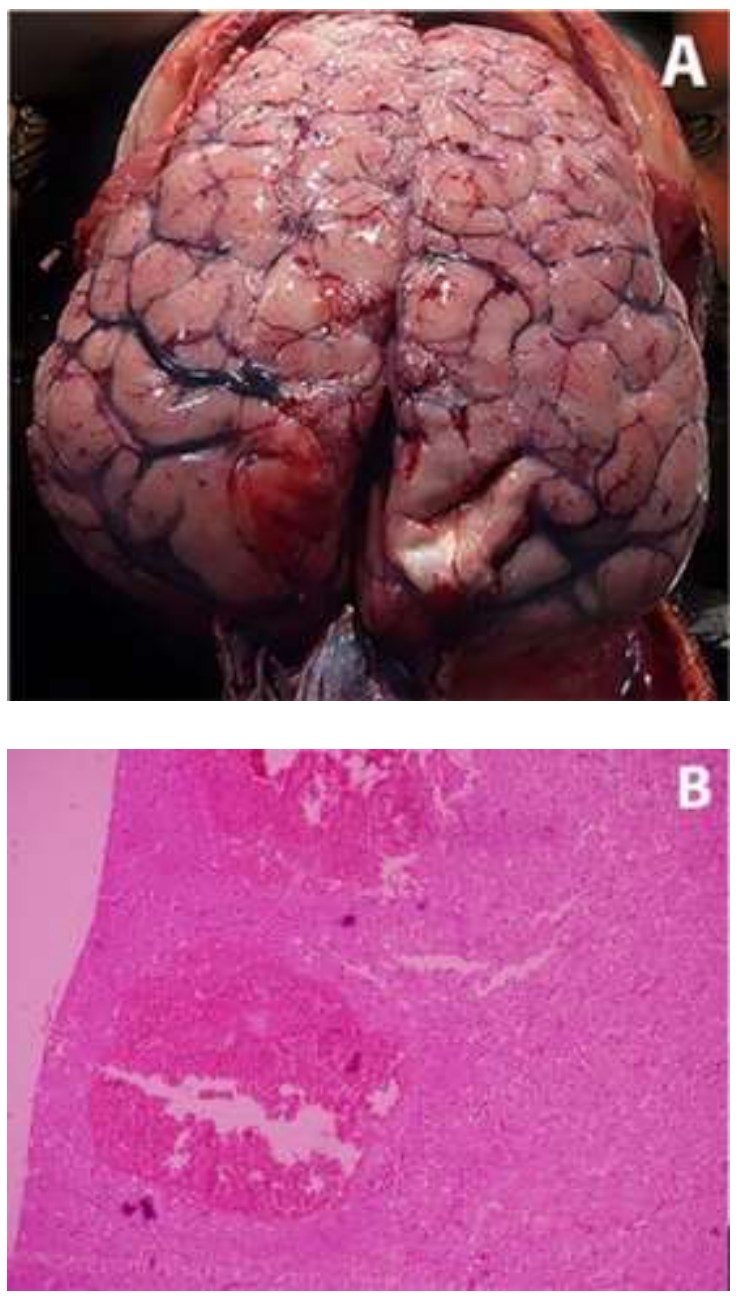

Figure 01. A. Oedematous and congested brain. B. Focal haemorrhages due to necrotizing vasculitis $(\mathrm{H}$ \& E $x$ 10)
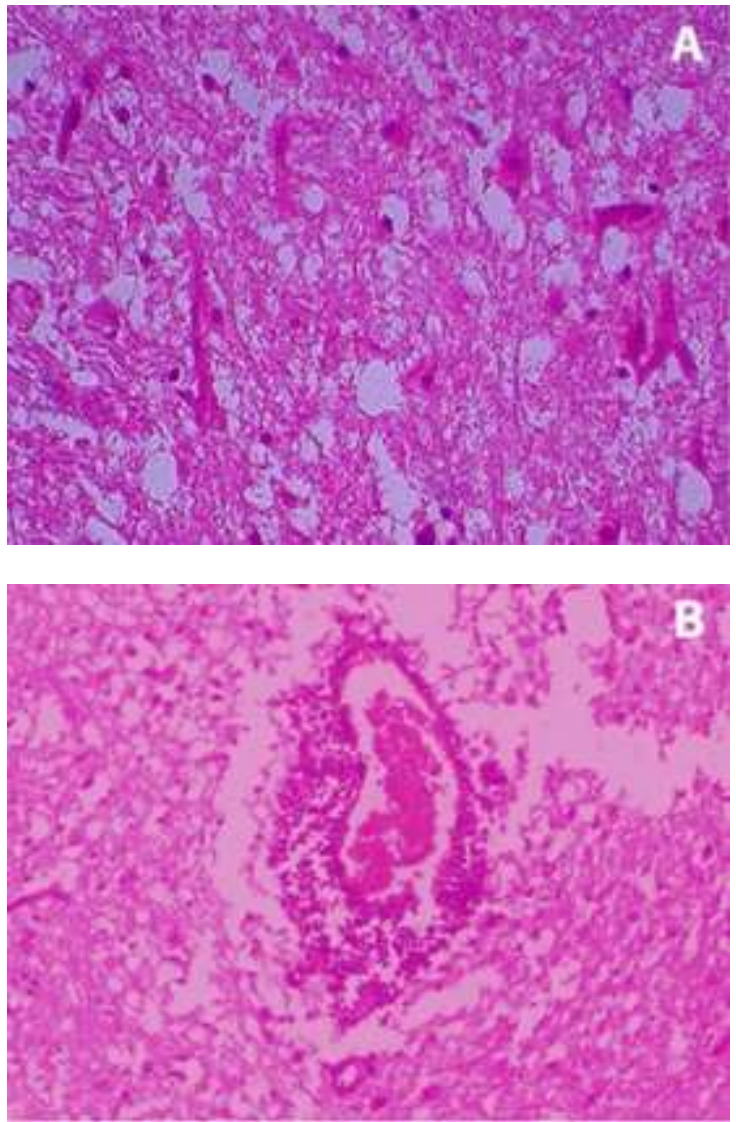

Figure 02. A. H \& E x 40 photomicrograph: Diffuse oedema of the brain. B. H \& E x 40 photomicrograph brain; mononuclear cell infiltration as perivascular cuffing (a characteristic feature of viral encephalitis) was identified. No intra-nuclear and cytoplasmic inclusions or Negri bodies were identified.

The liver showed central congestion with patchy necrosis and the kidney showed granular casts and red cell casts (Fig: 3). The clinical diagnosis was confirmed at the postmortem as acute viral encephalitis.

The parental grief reaction was immense in that situation and it was extremely difficult to convince them. The delay in admission was inquired from the parents. No valid reason was brought forth by them.

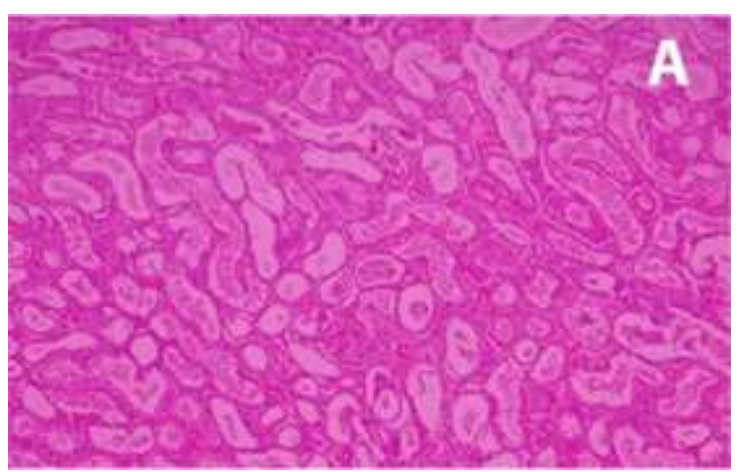




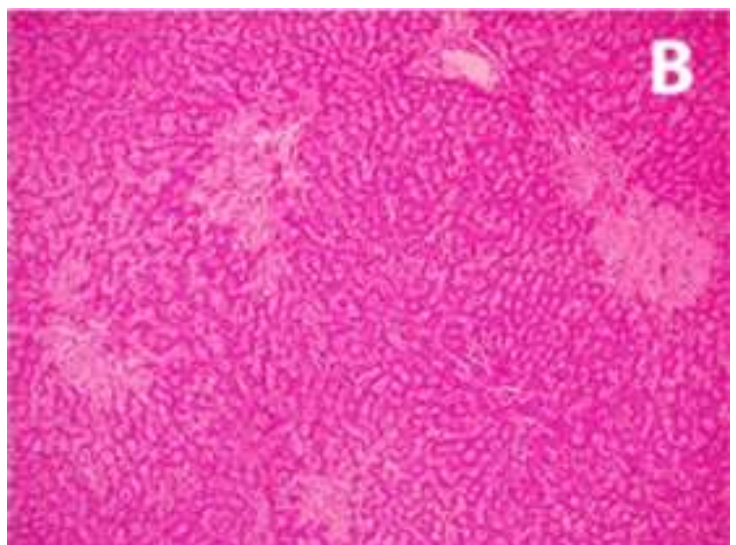

Figure 03. A. H\&Ex40, granular casts and red cell casts in renal tubules. B. photomicrograph of liver cell necrosis (H \& E x 40).

\section{Discussion}

The paper discusses the following aspects: the common causes of viral hepatitis based on limited literature, a possible causative agent of this case, delay in diagnosis and, the intense grief reaction of the parents.

In general, there are two broad categories from which encephalitis would result: direct infection by microbial agents (bacteria, fungi, viruses, and parasites) and by immune-mediated mechanisms. For viral aetiology the number of viruses that can be listed is limitless though the most common are the Herpes Simplex virus (HSV)-1 (fatal sporadic encephalitis), herpes viruses HSV-2, varicellazoster, cytomegalovirus, Epstein-Barr, Human Herpes virus (HHV), paramyxoviruses (measles, rubella), orthomyxoviruses (influenza A virus); enteroviruses (EV 70 and 71, polio, echo- and coxsackie viruses, flavi viruses (West Nile, Japanese encephalitis, dengue and Zika viruses), retroviruses (human immunodeficiency virus), alphaviruses (Venezuelan equine-, eastern equine-, western equine-encephalitis), bunya viruses ( $\mathrm{La}$ Crosse virus), rhabdo viruses (rabies virus), parvovirus (B19), Astroviruses and recently emerging viruses. Given the circumstances in Sri Lanka, the aetiological viruses are poorly recognized, and relatively poor emphasis has been made to maintain proper surveillance of such viruses. ${ }^{[3]}$

One of the earliest studies performed in 1968 was able to isolate the Sri Lankan Japanese encephalitis virus (JEV). ${ }^{[4]}$ The only virus that had been studied to some extent until recently was the JEV and it had been identified in some endemic areas: in the Western coastal belt up to the Northern Province. A study had identified varicella-zoster and its prevalence was 9\%. ${ }^{[5]}$ In 2019, the first two reported cases of Hanta virus were published. ${ }^{[6]}$ West Nile virus (WNV) had also been recognized in Sri Lanka as a zoonotic infection similar to Hanta virus, for the first time causing meningoencephalitis in 2015. ${ }^{[7]}$ Dengue has been one of the leading causes of morbidity and mortality in Sri Lanka over the past few years and it has also been recognized that the dengue virus is capable of causing encephalitis in Sri Lanka. $^{[8]}$

One of the inspiring researches done related to viral aetiologies in Sri Lanka has revealed that it was only possible to identify the aetiologies in $25 \%$ of patients. That study was able to identify, three cases of VZV, three cases of EBV, seven cases of JAE virus, eleven cases of dengue virus, and three cases of West Nile virus in Sri Lanka. Further, the same study highlighted that JE is the only virus on which epidemiological studies have been done so far.

Brain biopsies are not encouraged in suspected cases of encephalitis (exceptions may be there) and the only way to study the histology of the brain is by the postmortem samples. Perivascular cuffing, predominated with lymphocytes were noted (Fig.2 B) in this case confirming the diagnosis. Patchy necrosis of the brain and focal haemorrhages (Fig: 1B) due to vasculitis that is usually seen in severe cases were also noted as complications of the disease. There had been continuous fits after the admission resulting in myoglobinuria and acute kidney disease and it was evident histologically as well. Granular casts were evident along with nephritis and red blood cell casts were also present. Congestive heart failure was also evident indicating central venous congestion of the liver. Patchy liver necrosis was able to be explained by the sepsis that had proceeded.

Since published literature in Sri Lanka is limited, the epidemiology of encephalitis is also limited. ${ }^{[9]}$ According to the published data by the WHO in $2018,0.29 \%$ of deaths were attributed to encephalitis from the total deaths and it was 363 in number. ${ }^{[10]}$

In this case under discussion, there had been a delay in hospital admission of almost three days till the girl lost her consciousness. That period may have adversely affected the optimal treatment. ${ }^{[9]}$ The patient was admitted with a history of high fever, vomiting, altered consciousness, and a fit. But only by day 5 of the illness, was the condition diagnosed as an infection of the central nervous system. There had been enough clinical signs and symptoms to differentially diagnose the condition as encephalitis or meningo-encephalitis by the hospital doctors. During the ICU management, the blood culture was positive for Acinetobacter species indicating hospital-acquired infection adding an important point to be emphasized in this case. It could have contributed to further deterioration of the sepsis. Encephalitis in deed is a disease where the fatality 
rate is high. However, it is worthwhile to discuss the importance of early diagnosis after admission. The author stipulates that delayed admission may have had a negative effect. Anyhow the author observed how the death of an immediate family member adversely affected the whole family. The younger siblings were neglected by the parents as they indulged in grief. Based on the above facts, it would be a better idea to establish centers to address grief when necessary.

\section{Conclusions}

The underlying aetiological agents of viral encephalitis remain mostly unknown despite the advancements in molecular diagnostic methods. The epidemiology of viral encephalitis has not widely been studied in Sri Lanka. Awareness of the epidemiological patterns along with demographic data would direct a physician in the right direction of diagnosis even with the lack of expensive investigations. Because of the endemic nature of dengue, encephalitis of tick-born aetiologies, and novel viruses such as severe acute respiratory syndrome coronavirus 2 (SARS-CoV-2) including other novel viruses, epidemiological studies are widely warranted. Since a brain biopsy is rarely indicated, histopathological studies of postmortem samples bear a significant place. The delay in diagnosis despite the highly suggestive signs and symptoms is to be revisited by the clinicians. When a clue suggesting hospital acquired infection is evident, prompt actions are to be taken by the hospital. Grief is not an entity to be overlooked when it reaches a severe level as in this case. Grief reaction of next of kin is an inherent "occupational hazard "experienced by forensic pathologists. Establishing counselling centers attached to JMO's offices at least at provincial levels in order to address the grief of next of kin should also be introduced as a necessity.

\section{Acknowledgments}

Mrs. SC Kaluarchchi (Technical Officer), EMMS Ekanayaka, ADA Vimukthi, JAN Kawshalya, RADLD Ranawaka, AI Rangika, and KDS Chandimal of the Department of Forensic Medicine, USJ for preparation of histology slides and the miscellaneous support, Dr. Sherin Suzai (Consultant Histopathologist), Colombo South Teaching Hospital, Dr. DMB Thushari Dissanayake (Senior Lecturer/Clinical Microbiologist, Department of Microbiology, USJ) for providing opinions regarding pathological and microbiological aspects, Dr. Dulani Beneragama (Senior Lecturer/Consultant Histopathologist, Department of Pathology, USJ) for assisting in reading of histopathology slides, for micro-photographing Mr. MSE Premalal (Technical officer) from the Department of Pathology and Ms. MW Sooriyarchchi, Ms. WMCW Menike, Ms. NGH Kawushalya from the Department of Parasitology,
USJ. Mr. Wasantha Manawadu for the IT assistance (Technical Officer, Dean's office, USJ).

\section{Disclosure statement}

Conflicts of interests: The authors declare that they have no conflicts of interest.

Funding: None

\section{References}

1. Venkatesan A, Geocadin RG. Diagnosis and management of acute encephalitis. Neurol Clin Pract 2014;4(3):206-15. DOI: 10.1212/CPJ.0000000000000036

2. Death from encephalitis. The Encephalitis Society. [cited 2020 Oct 11]. Available from: https://www.encephalitis.info/death-fromencephalitis

3. Lohitharajah J, Malavige N, Arambepola C, Wanigasinghe J, Gamage R, Gunaratne $\mathrm{P}$, et al.Viral aetiologies of acute encephalitis in a hospital-based South Asian population. BMC Infect Dis $2017 ; 17(1)$ : 303. https://doi.org/10.1186/s12879-017-2403-z

4. Gunasekera H, Senanayake CP, Mendis L, Chandra NS. Japanese encephalitis virus infection in an endemic area: hospital-based study 1998 to 2000. Sri Lankan J Infect Dis 2012 31;2(1):19-27. DOI: http://doi.org/10.4038/sljid. v2i1. 3321

5. Gunathilake DL, Ramesh R, Wickramasinghe N, Abeynayake J, Galagoda G. Varicella-zoster virus as a cause of infectious encephalitis in a cohort of Sri Lankan patients. Ceylon Med J. 2016;61(4):196.

DOI:http://doi.org/10.4038/cmj.v61i4.8392

6. Ehelepola NDB, Basnayake BMLS, Sathkumara SMBY, Kaluphana KLR. Two Atypical Cases of Hantavirus Infections from Sri Lanka. Case Rep Infect Dis. Hindawi; 2018. 4069862. https://doi.org/10.1155/2018/4069862.

7. Lohitharajah J, Malavige G, Chua A, Ng ML, Arambepola C, Chang T. Emergence of human West Nile Virus infection in Sri Lanka. BMC Infectious Diseases. 2015;15(1) :1040-7. DOI:https://doi.org/10.1186/s12879-015-1040-7

8. Weerasinghe $\mathrm{W}$, Medagama A. Dengue hemorrhagic fever presenting as encephalitis: a case report. Journal of Medical Case Reports. 2019;13(1):278. DOI: https://doi.org/10.1186/s13256-019-2201-x.

9. Ranawaka UK. The challenge of treating central nervous system infections in the developing world. J Ceylon Coll Physicians. 2018 29;49(1):2-15. DOI: 10.4038/jccp.v49i1.7840.

10. Encephalitis in Sri Lanka. World Life Expectancy. [cited 2020 Oct 11]. Available from: https://www.worldlifeexpectancy.com/ sri-lanka-encephalitis 